\title{
Design and Implementation of multiple training model system based on safety perspective
}

\author{
Xu Yang \\ Center of Engineering Training, Shenyang Aerospace University, Shenyang 110136, China.
}

242884956@qq.com

Keywords: Engineering training, safety education, cause analysis.

\begin{abstract}
Multiple types of hybrid training is an important way to cultivate students' engineering practice and innovation ability, and an important way for students to personally contact product design, manufacturing, testing of the whole process, but because of their special content and methods of teaching, a lot of teaching often lead to security accidents. Taking Shenyang Aerospace University, for example, combined with its experience in recent years to ensure the safety and training under accumulation, the paper multi-angle discussed security issues and countermeasures training centers and incident handling processes, from a technical, training organizations, psycho physiological, and other aspects of teacher quality requirements as a foothold.
\end{abstract}

\section{Introduction}

With the reform and development of higher education, teaching, engineering training is also expanding the scale of construction, increasing the number of students, a lot of training content development, diverse forms of teaching, engineering training opportunities for students to receive more and more, the more benefit from the surface to the more widely. Engineering colleges engineering training made more and more types of hybrid teaching model of education reform, which had remarkable achievements in fostering students' innovative ability, but more special content and methods of teaching, there have been more accidents. The students will each design a work often exposed to many types of work, such as reducer housing (as show in the Figure 1), you need to cast blank, multiple processes welding repair defects, milling milling plane, fitter drilling to complete a work. It seems that such students should contact more equipment, more of the production process, this will bring more security problems. Students do not have a wealth of practical experience to enterprise workers, students only just contact, did not encounter accidents during emergency handling capability. Such as teaching anti-spray phenomenon when casting casting process, there will be time for enterprise employees will soon spray a dodge, and when the student is in the liquid metal blast dancing, only to dodge; teaching when casting defect repair welding, arc often occur light glare and metal burns phenomenon, mainly students of arc welding process caused by incorrect; during milling, due to the student's processing capacity, feed rate of inappropriate choice, often cause the tool to break, pop fly wounding; when the lathe chuck wrench forget when employees of enterprises will be instantaneous and student Lai Buji side head to dodge the tune to dodge; these are experienced will be able to overcome the inevitable and so on.

Multiple types of hybrid innovation training and basic training is different, there is a big difference, for security requirements are not the same, in the context of multiple types of hybrid innovation training proposed safety education is more important, and more jobs for its teaching of particularity, diversity, students hyperactivity, complexity, freshness of machined parts, easier to lead to accidents. 


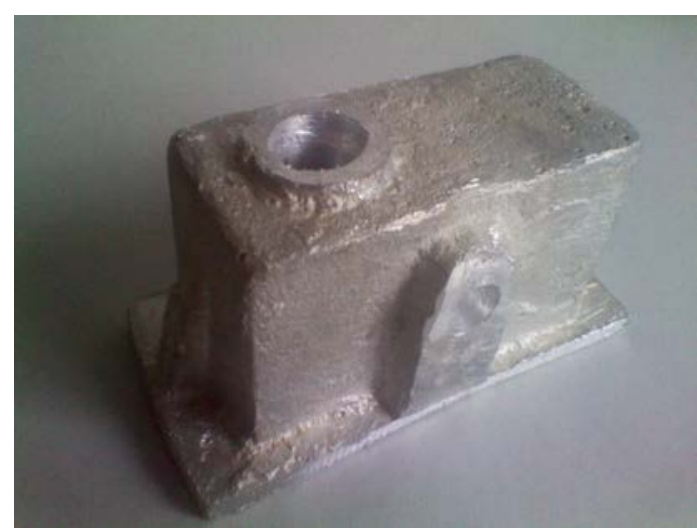

Fig. 1 reducer housing

\section{Engineering training accidents cause analysis}

Multiple types of hybrid relatively basic skills training brings more security problems, just a good sum up experience, in order to provide a better foundation for future training. Now the years of practical teaching work to do in order to summarize:

(1) The reason of technical, mainly by training in labor protection equipment, engineering and technology programs of structural defects caused by imperfect process engineering, equipment, tools, instruments imprecise caused accidents. More college classroom or factory by the transformation from mechanical equipment without protection, no safety device, no alarm, no safety warning signs, unlimited digital device, ungrounded electrical equipment, poor insulation, noise and large more problems easily lead responsibility for security incidents. Students arrange the operation process is unreasonable, but also easily lead to excessive production cross accidents.

(2) The reason of organizational, including inadequate supervision on the training process, labor organizations unreasonable, producing low skills, lack of knowledge and experience. Deepen practical teaching process safety management, in order to be able to process the entire training, supervision can be a good time, we propose Leader safety responsibility. Relying solely on safety instructor responsible for teaching when mixing is not enough, especially an instructor with multiple teams in multiple jobs simultaneously is not enough, we have outstanding performance by selecting training at the basis of as the head of the students, through professional safety and skills training, safety management and skills to bear part of teaching, training and management of student aid in the process of teaching, that learned knowledge and improve the comprehensive ability, but also reduces the teacher's safety center administrative workload, boosting the teaching engineering training and more types of hybrid propulsion. Students skills to enable students to think, see more operations, thereby improving operational skills, we also successfully held two sewing skills competition, have been leaders and students alike.

(3) The reason of Psychological and physiological, namely training and pay attention to safety, the students relaxed self-monitoring, workplace layout ignored the physiological characteristics of the human habit. As students just contact mechanical product design, fabrication, assembly, testing the entire process, the practical operation of this distinguished teaching theory was both strange and curious, will produce hyperactivity or fear of psychological; less production experience, the lack of relevant safety knowledge protect yourself and others is not strong awareness; multiple types of hybrid teaching students fled when making large, easy to manage, contact jobs frequently, often alternating operation; still rebellious attitude, always feel that he is right, over-confident, do not listen teacher while secretly working privately, even barbaric operation, resulting in serious consequences. Therefore, we need to care for the health of teachers and students to protect the lives and safety of students and teachers as a starting point, always put the safety of students and teachers in mind. Therefore, in engineering training, strengthen safety management, and actively guide students and teachers to build a safety culture to ensure that teachers and students safe is our bounden duty. 
(4) The reason of instructor

First instructor should have advanced safety awareness, "Safety should be based on prevention" in their daily teaching, the instructor should be vigilant, not accustomed to "no accidents do not know, out of the surprised", "no accidents do not care to find out the cause of the accident" behavior way, but should prevent the accident, so the instructor must be forward-thinking, that security issues should guard against the former, think first and do the former.

Secondly instructor should have a serious and responsible attitude, Practical guidance is a very practical work, so careless and false, so the instructor must have a high sense of responsibility and a serious and responsible attitude, always, everything, everywhere expect the operation and safety of students. Have a global concept, the students can not see any imminent danger to other groups and doing whatever.

The instructor shoud have rich practical experience, be familiar with the production process of the present work, to understand the performance of, the steps, the operating requirements of the major types of production equipment, and to resolve technical issues on the practice of teaching.

Last good demonstration of theachers is also important, no good demonstration of teachers, it is difficult to achieve student voluntarily comply with safety system. Conscientiously carry out safety training standards group activities, a person illegal, collective offense, team members realize mutual restraint, common supervision, job constraints behavior achieved very good results.

Center for the instructor to implement quantitative assessment system, appraised and year-end titles qualify as a security incident implement veto system, more effective incentives for active and serious participation in the teaching guide.

\section{Engineering Training Security Incident Response Measures}

Once security incidents, emergency treatment center must do the work to minimize losses caused by the accident on the center. In the case of self-performance of the students are not familiar with the machine and the skill of the operator is not high or relax, there must be the possibility of operational errors due to security incidents, and therefore affect the safety training for all kinds of work these exist, I think we should from to improve the following aspects.

(1) Each group of students insist on proper safety safety education, especially tertiary education training room, and safety education to effectively integrate and professional skills training. According to reports, after college security practitioners by injuries increases every year, there are a number of accidents caused by human factors entirely, the operator can avoid a slight safety knowledge. Instructor training program should describe the production characteristics of the working environment, hazardous areas, equipment condition and fire facilities.

(2) ensure that machinery and equipment in the best condition, so that each student can guarantee when multiple types of operating multiple devices, are able to complete more smoothly. Do not understand the state of the device in order to avoid the risk of causing an accident.

(3) unsafe student behavior, student inadvertently or because of negligence. Training room students are more easily frolicking, when the operation could easily lead to inattention, resulting in accidents, to serious training discipline. Do not operate hand tools instead of the workpiece or tool contact with high-speed rotation. Operation, should always ask students to wear good labor protection products, in order to avoid burns and other welding.

(4) instructor strengthen management. On the rules and regulations must be strictly enforced, and actively inspect each machine, timely guidance to students when operating errors operations. Strengthen supervision of teachers counterparts.

(5) leaders to raise awareness and actively patrol security risks, active rectification. Establish and improve the safety inspection agency, to establish and implement safety training responsibility is to make security work into all aspects of practice teaching, to achieve full, comprehensive, secure management of the entire process, to ensure the safety training. 


\section{Major security incident handling process}

To ensure the personal safety of students, the timely processing of sudden major accidents, according to the "significant safety engineering training center emergency treatment plan," formulated the following emergency treatment processes.

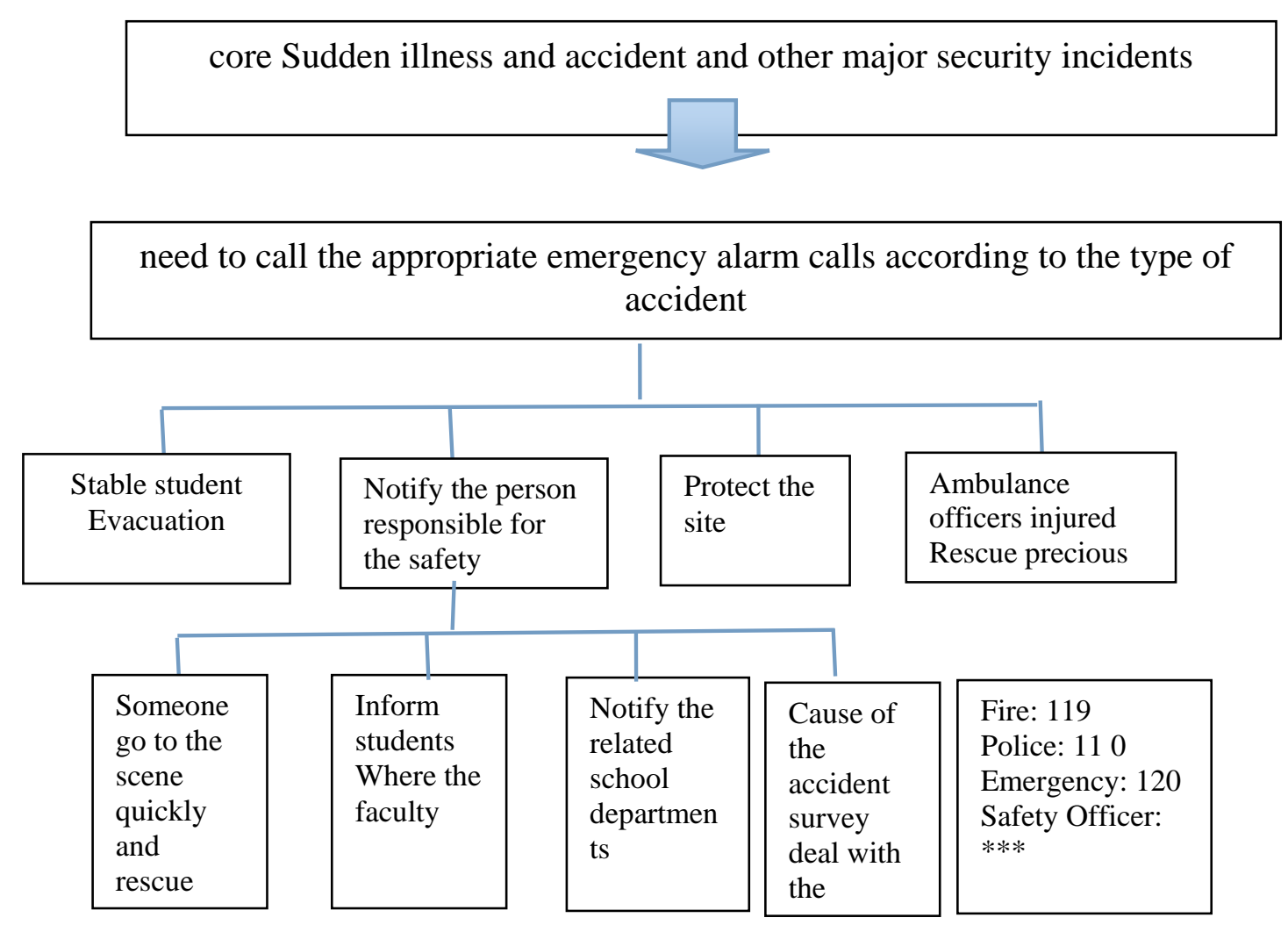

Fig.2 major security incident response center processing

\section{Conclusions}

Safety training management long way to go, you need to practice constantly sum. By summing up the reasons for accidents, so that teachers and students get promoted in the craft skills, responsibility attitude, spirit, ideas, habits, cultural training, etc., to form the correct security thinking, safety awareness, safety psychology, safe behavior, so much types of hybrid innovation training healthy and orderly conduct, so as to effectively develop students' practical and innovative ability.

\section{References}

[1] H.J. Yang: Safety Management for Factors by Figure (People Post Press, China 2014), p.49-50. (In Chinese)

[2] L.N. Ye: Outside School Education of China, (2009) No.8, p.49-349. (In Chinese)

[3] F.W. Zou: Laboratory Research and Exploration, Vol. 29 (2010) No. 2, p.181-183. (In Chinese)

[4] M.C. Xie: The Study of University Laboratory, (2013) No. 4, p. 62-64. (In Chinese). 